\title{
Beyond the Frontstage: Trust, Access, and the Relational Context in Research With Refugee Communities
}

\author{
Kenneth E. Miller ${ }^{1}$
}

\begin{abstract}
This paper examines the role of trust and the concept of access as they affect the relational context in which community research, and research with refugee communities in particular, is conducted. Sociologist Irving Goffman's metaphor of frontstage and backstage behavior is used to illustrate the complexity and importance of developing of relations of trust, and thereby gaining "backstage" access, in communities that are generally closed to outsiders. It is argued that gaining authentic ("backstage") access to refugee communities, as well as other communities that have developed a self-protective insularity, is essential if we are to gather data that accurately reflect the actual beliefs, feelings, and experiences of community members. The paper then examines the puzzling lack of discussion regarding issues of trust, access, and the relational context in the literature on refugee mental health. Explanations for this apparent inattention are sought in the influence of the prevailing scientific paradigm that guides most research with refugees, and that shapes the values of the field's "gatekeepers," the editors and reviewers of scholarly journals. Throughout the paper, key points are illustrated with examples drawn from the author's research with refugees from Guatemala, Bosnia, and Afghanistan.
\end{abstract}

KEY WORDS: research relationship; trust; refugees; community.

\begin{abstract}
The mythology of hygienic research, with its mystification of the researcher and the researched as objective instruments of data production must be replaced by the recognition that personal involvement is more than dangerous bias-it is the condition under which people come to know each other and admit others into their lives.
\end{abstract}

(Oakley, 1981, p. 58)

This paper examines the role of trust and the concept of access as they affect the relational context in which community research, and research with refugee communities in particular, is conducted. I am concerned here with how we actually enter the worlds of those who are the focus of our research, particularly when our research concerns the experiences of communities that have developed a self-protective insularity in response to their experiences of marginalization and oppression. Those of us who are outsiders to the

\footnotetext{
$\overline{{ }^{1} \text { To whom }}$ correspondence should be addressed at Psychology Department, San Francisco State University, 1600 Holloway Avenue, San Francisco, California 94132; e-mail: kemiller@sfsu.edu.
}

communities that are the focus of our research cannot simply waltz in unannounced and start gathering data. Nor, of course, would we want to do so. Participation would presumably be quite low and/or superficial, and the prospects of our research having any long-term, positive impact would be minimal. Instead, there is an essential process-the process of developing relations of trust and thereby gaining access-that occurs prior to conducting effective research within communities which, because of their difficult histories, are understandably guarded in their interactions with "outsiders." Which brings me back to my original question: how is it that we, or at least those of us who are "outsiders," actually enter the communities in which we work? How are we able, despite the community's insularity, to gain the kind of access that will permit us to gather data that accurately reflect the authentic experience of community members?

The answers to these questions should presumably be available in the published reports of researchers who have gained access in their work with 
communities where issues of trust and access are particularly salient. In fact, however, these issues are rarely addressed in the reports of research conducted in such communities. With specific regard to refugees, it is in fact the exceptional article that includes any discussion of the research relationship. Typically, little if any mention is made of how the researchers were able to enter the refugee communities in which they worked, or to what extent they were able to develop the sort of trusting relations that might have inclined the participants in their studies to provide truthful, accurate data. Data are typically presented as valid representations of community members' beliefs, feelings, and behavior, with minimal or no consideration of the ways in which participants' perceptions of the research relationship may have influenced their responses to interview questions or questionnaire items.

In my own experience, I have found that entering refugee communities is a complicated process that takes time, negotiation, and a respect for the gradual development of relations based on trust and mutual respect. Even under the best of circumstances, this can be a challenging experience with its share of missteps and moments of uncertainty. The paucity of discussions of this process in published reports of research with refugees is thus a bit of a puzzle, reflecting, I suspect, two primary factors: (1) the paradigmatic framework that continues to guide much of the research on refugee mental health and (2) a perception among researchers who are addressing issues of trust and access in their work with refugees that journal editors are not especially interested in discussions of such issues. Each of these putative factors is explored below.

In this paper, I hope to put the concepts of trust and access center stage, and to illustrate, by drawing on examples from my research with refugees from Guatemala, Bosnia, and Afghanistan, the power of the relational context of our research in determining the quality of the data we gather. I have used Goffman's (1959) metaphor of frontstage and backstage behavior to illustrate both the complexity and importance of developing relational contexts that are based on trust and that permit us to gather meaningful data, in communities that are generally closed to outsiders. I briefly examine the paradigmatic lenses through which community psychologists, and in particular those of us who work with refugees, have viewed such issues, and conclude by offering a rationale for incorporating discussions of trust, access, and the relational context in our research publications. Although the focus of this paper is primarily on work with refugee communities, I hope this discussion will be germane to researchers working with other communities where issues of insularity, and thus of trust and access, are equally salient.

\section{DEFINING THE KEY CONSTRUCTS: TRUST, ACCESS, AND THE RELATIONAL CONTEXT}

\section{Trust}

Early in the process of developing their research project with a Black South African community that had recently been attacked by right wing vigilantes, Dawes, Tredoux, \& Feinstein (1989, p. 19) found it necessary to establish relations of trust with community members prior to actually conducting their research:

\footnotetext{
The researchers and their team had to make clear their personal opposition to what had occurred in the area and to apartheid. Without these provisos, access to the area would not have been possible. Several South African researchers have noted the necessity of declaring one's political position in order to conduct work of this type.
}

In my own research with Guatemalan refugees in southern Mexico (described below), the importance of developing trusting relationships was similarly salient:

\footnotetext{
My research in the refugee camps would not have been possible without my having been willing to make explicit, time and time again, my opposition to the policies and practices of the Guatemalan government and military. Guatemalan Indians are extremely wary about revealing their personal views to outsiders (i.e., people not from their community). To have insisted on a stance of political neutrality in the face of the extraordinary repression the refugees have endured, would have been regarded as both insulting and threatening, and any cooperation I received with my research would have consisted of polite and meaningless responses. More likely, however, I would not have been invited to live and work in the communities. (Miller, 1994, p. xiii)
}

These quotes illustrate the salience of trust as a methodological issue in research with socially marginalized, politically oppressed communities. In such communities, the development of trusting relations is a prerequisite to conducting any sort of meaningful research. It is interesting, however, to note that the concept of trust as a methodological concern has received relatively little attention in the psychological literature. Although this oversight may stem from various factors, I would suggest its roots lie at least 
partly in academic psychology's historical adherence to the tenets of logical positivism and its more recent postpositivist derivatives (Guba \& Lincoln, 1994), according to which questions of trust are deemed largely irrelevant to the research-subject relationship (Guba \& Lincoln, 1994; Harding, 1991). The concept of trust implies the existence of an authentic interpersonal relationship, something which social constructivists and other critical theorists regard as essential (FosterFishman, Salem, Chibnall, Legler, \& Yapchai, 1998; Gergen, 1985), but which, from a positivist perspective, is seen primarily as a potential source of bias to be controlled, and if possible, eliminated. From the latter point of view, the ideal research relationship is impersonal, objective, and unbiased by the personal reactions of researchers and participants to one another (Guba \& Lincoln, 1994).

Beginning in the late 1960s, community psychologists began questioning the legitimacy of this impersonal paradigm and its appropriateness as a framework within to conduct community research. In its place, an ecological model was put forth, in which relations of trust and mutual respect were deemed not merely desirable, but essential to the conduct of meaningful research in communities (e.g., Kelly, 1970; Trickett, 1984). Currently, there is a small but growing group of community-oriented psychologists whose work with refugees is grounded in this ecological framework (e.g., Boothby, 1996; Goodkind, Hang, \& Yang, 2004; Miller, 1999; Saenz, 1994; Wessells \& Monteiro, 2004). Overall, however, the ecological emphasis on building trust within the researcher-participant relationship has thus far had a limited impact on research with refugees, where much of the research continues to be guided by the medical/psychiatric model of clinical psychology and psychiatry (a model rooted squarely in the positivist tradition). This lack of an ecological emphasis can be seen in the extent to which the relationships that pertain between researchers and the participants in their studies are still treated in rather peripheral terms, to the extent that they are addressed at all. The vast majority of published studies on the mental health of refugees provide little or no information regarding the nature of the research relationship, and, of equal importance, offer no reflection on the possible impact of that relationship on the data provided by participants. Findings are presented as factual, particularly if they are based on so-called "objective" data gathering methods (e.g., self-report questionnaires); the possibility that participants may shape their responses based on the relative degree of trust they feel toward the researchers is simply not considered.

To illustrate the salience of trust as a methodological issue in research with refugees, I offer two examples from my research with Guatemalans living in southern Mexico. In 1992, Debbie Billings and I, both graduate students at the time, conducted research in two Guatemalan refugee camps in the Mexican state of Chiapas. Both camps were situated in close proximity to the Guatemalan border, and the Guatemalan army had made several incursions into the larger of the two camps in previous years. The two camps differed according to such variables as size, ethnic composition, rates of bilingualism (i.e., the extent to which residents spoke Spanish as well as their primary indigenous language), openness to outsiders, access to land, degree of gender differences in access to valued social roles, and availability of nearby wage labor. The residents of the larger camp had fled from their villages in 1982, following word of massacres in several nearby communities; the residents of the smaller camp were survivors of a massacre in 1982 in which soldiers killed at least 16 community members in a single day. This violence was part of a widespread government-orchestrated plan of mass intimidation and repression designed to silence growing demands for changes to the oppressive socioeconomic and political status quo (Handy, 1984; Manz, 1988). Between 1978 and 1985, over half a million Guatemalan civilians, the majority of them indigenous Guatemalans from rural villages in the highlands, had been forcibly displaced from their homes and communities (Handy, 1984; Manz, 1988).

Our research, which used a mixed qualitativequantitative design, examined children's mental health and adaptation to the stressors of exile (Miller, 1996, 1994), as well as women's experience of, and adaptation to, life in the camps (Billings, 1996). While in the camps, we also collaborated with the community's schoolteachers on the adaptation and implementation of an preventive mental health intervention for children (Miller \& Billings, 1994) based on work in Guatemala and Argentina (Lykes, Maciel, Iborra, Suardi, \& Costa, 1991). We had been invited by a Mexican colleague to affiliate ourselves with a local health research organization that had worked in the camps, and after a somewhat complicated process of introduction to the communities' elected representatives (described below), we were eventually invited to work in the camps. During the first few weeks of the 8 months that we worked the larger camp, we would enter community early in the morning, then leave each 
evening to sleep in the cramped quarters of our pickup truck on the outskirts of the community. Although guest quarters were available in the community, we had not yet been invited to stay in the camp and did not feel comfortable asking permission to do so. Our interactions with community members felt strained, and we often had the sense that we were regarded with considerable wariness-understandable, given the community's history of exploitation and oppression, but somewhat frustrating to us nonetheless. One morning, a 10-year-old boy knocked on the window of our truck as we slept. He explained that his father, a respected community member to whom we had recently offered a ride and with whom we had shared a warm conversation, had invited us to stay in the family's home as long as we continued working in the community. That generous invitation from a highly regarded family served as a powerful signal to the community that it was both safe and acceptable to interact with us. We experienced a significant shift as community members began to express interest in our work and an openness to interacting with us, both informally and through more formal research interviews. The trust evidenced by our host family greatly facilitated our acceptance within the larger community.

In the smaller of the two refugee camps, where we worked for only 6 weeks, we were initially struck by the harmonious environment, and by the warmth and cooperation that appeared to guide most social interactions. Although this impression was to some extent accurate, it was only on our last day, as we chatted with a family with whom we had become particularly close, that we learned of instances of child and spouse abuse, as well as a recent incident involving the schoolteachers that had caused considerable dissension and had in fact deeply divided the community. None of this information had surfaced in any of our previous interviews or informal conversations with community members. It was only once we had established a mutually supportive and trusting relationship with a particular family that members of that family felt comfortable revealing some of the "backstage" truths of their community (Goffman, 1959). It is also possible that our imminent departure from the camp made it safer for the family to share with us their perceptions of ongoing conflicts and problems within the community. Had we left prior to this revealing interaction, our image of the community, and our interpretation of the data we had gathered, would have been shaped more powerfully by the frontstage behavior we had observed. This "backstage" data permitted us to develop a more accurate, less idealized depiction of the community, one which captured its numerous strengths and resources, as well as some of the challenges and complexities inherent in community life.

It is noteworthy that relations of trust with community members in both refugee camps were enhanced by Debbie's and my having lived and worked in Guatemala with indigenous communities before moving north to Mexico. Although we had not been to all of the communities from which the camp residents had fled, we had lived in the largely Indian highlands and our work had taken us to some of the most devastated regions of the country. Debbie had worked with weaving cooperatives run by and for women widowed by the violence of the early 1980s, and I had worked as a mental health consultant to a highland health organization that worked with rural communities. These experiences in Guatemala lent us some degree of legitimacy as we interacted with community members in the refugee camps; not only did they give us some understanding of where the refugees had come from and what they left behind, but they also underscored our commitment to the well-being of those affected by the state's violence. Although no one commented directly on the value of our having lived and worked in Guatemala, upon learning of our prior work people generally responded with a greater degree of openness regarding the stories they shared of their lives in Guatemala and of the difficult journeys they had made into Mexico.

\section{Physical and Interpersonal Access}

\section{Physical Access}

By physical access, I refer to the extent to which researchers are able to actually physically enter the boundaries of a particular community, as a prerequisite to gathering data from community members. In research with refugees, this is not necessarily a straightforward matter. Access to refugee camps in certain regions of the world is carefully controlled by local authorities, whereas in other camps, community members themselves may carefully monitor who is and is not to be allowed to enter the community. There is also the matter of actually making one's way to the camps, which are often located in remote areas, sometimes in close proximity to regions of ongoing conflict (Mayotte, 1992).

To illustrate the concept of physical access, I offer another example from my work with Guatemalan 
refugees living in southern Mexico. When Debbie and I first arrived at the larger of the refugee camps in which we worked, the trip itself was uncomplicated, as the Mexican army was not yet restricting access to the camps as they would subsequently do once the Zapatista uprising erupted 2 years later throughout the state of Chiapas. The camp was a sprawling community of 200 families nestled in the Cuchumatan mountains that lie along Mexico's southern border with Guatemala, and was accessible by a combination of bus, van, and foot along dirt roads and winding mountain paths. A friend of ours who had a long history of working in this particular camp had arranged a meeting for us with the camp's elected representatives so that we might discuss the reasons for our wish to work in the community. During the meeting, we briefly discussed our research interests, but focused primarily on our offer to train the community's schoolteachers in the preventive mental health project mentioned earlier (Miller \& Billings, 1994). We were a bit surprised when the representatives responded by asking us for a bribe in order that we might be allowed to work in the community. The size of the bribe requested by the representatives was small, but the request itself was both disturbing and disillusioning. We had come a long way, with strong feelings of solidarity with the refugees, and this seemed a crass sort of welcoming. It also seemed to us something of a betrayal of the community members who had elected these individuals to represent them. After much deliberation, we declined to pay the bribe, and wondered with some anxiety whether we would be allowed to enter the community. In the end, the issue of the bribe was never mentioned again and we were granted unlimited access to the camp. When we subsequently related this experience to the family with whom we stayed in the camp, the parents expressed dismay at the representatives' behavior, and informed us that this group of representatives was viewed with considerable distrust by many community members for prior breaches of the community's trust. They also supported our decision to not pay the requested bribe, indicating that, had we done otherwise, we would have colluded with the representatives in betraying the community.

Researchers working with refugees in urban settings, rather than refugee camps, may also encounter obstacles to gaining physical access. In a recent study of Afghan refugees in the Bay area of California, which I conducted together with three Afghan women, themselves refugees, our focus was on young Afghan women who had been brought to the United States from Pakistan through arranged marriages made by their parents and the families of their wouldbe husbands. Word in the local Afghan community suggested that many young women in this situation found life in the United States quite difficult, with few sources of social support, highly restricted mobility, considerable isolation, and in some cases, physical abuse. Although the study had widespread support from local Afghan organizations and numerous individuals in the community, gaining access to the women themselves proved to be extremely difficult, as their husbands and in-laws, without even knowing the exact focus of the research, actively discouraged their participation in the study. In fact, many women were so frightened by the anticipated displeasure which their participation might evoke that they simply declined to be interviewed. In other instances, the women's relatives sat nearby throughout the interview, resulting at times in a form of self-censorship among participants, and in fact among the interviewers as well. Although creative solutions were eventually developed that permitted us to address some of these difficulties (e.g., identifying "safe" times when the women could speak freely, interviewing women who were no longer living with their husbands, and interviewing key informants who were knowledgeable about but not actually in this sort of arranged marriage), the experience underscored for us the salience of physical access as a methodological issue across a diverse range of refugee settings (Zahir, Kakar, Zahir, \& Miller, 2001).

\section{Interpersonal Access}

By interpersonal access, I refer to the extent to which researchers are able to actively engage community members as participants in their research. The failure to gain interpersonal access can occur when community members express a willingness to participate in a particular study, but then provide data that do not accurately reflect their actual feelings, beliefs, attitudes, and/or behaviors. This illusory interpersonal access into community members' lives can be a great threat to the validity of the data collected, precisely because we may not know that the stories we are being told, the responses indicated on our questionnaires, or the behaviors we are witnessing, are protective fronts that mask the more authentic data we hope to gather.

The late sociologist Erving Goffman's concept of frontstage and backstage behaviors is helpful in illuminating the distinction between illusory and authentic interpersonal access. By frontstage behaviors, Goffman (1959) referred to self-protective, often 
manipulative modes of behavior used with strangers, societally defined superiors, and others with whom one feels a limited degree of interpersonal trust and intimacy. Frontstage behavior is manipulative not in a pejorative sense, but rather, in that it is a performance designed to present a particular appearance, typically with the aim of achieving some desired effect (e.g., appeasing a superior, impressing a potential romantic partner, showing off to gain social status, etc.). Backstage behavior, in contrast, occurs when there is no longer any need to perform, for example, when an individual is alone, or finds him or herself in the company of trusted companions. It is here that "the performer can relax; he can drop his front, forgo speaking his lines, and step out of character" (Goffman, 1959, p. 112). It is in the realm of the backstage, Goffman suggests, "where the suppressed facts make an appearance."

The implications of Goffman's analysis for our understanding of interpersonal access in community research are twofold. First, in the absence of relations of trust between researchers and their participants, interpersonal access is unlikely, and participants may be inclined to offer "frontstage" responses when asked to provide data about personally meaningful domains of their lives. They may opt to respond according to what they perceive to be the researchers' expectations or desired responses; they may provide what they consider to be politically expedient answers; or they may seek to avoid personal discomfort by not revealing painful or conflictual information. In the absence of a trusting relationship, it is also likely that researchers will be insufficiently familiar with the context of their participants' lives to be able to recognize such "frontstage" responses as the protective fronts they are. The second implication of Goffman's analysis, which follows logically from the first, is that if we genuinely desire to gather meaningful data from those whom we hope to study, we must be willing to invest the time and energy to develop the sort of trusting relationships that will facilitate interpersonal access and the sharing of "backstage" information. Anthropologist Patricia Omidian (1996) illustrates the value of taking the time to achieve "backstage" access in her research with Afghan refugees in California. Referring to her evolving perceptions of an elderly female informant, she writes

When I first met her she seemed very happy, but I discovered that the happiness was part of her show of hospitality. As our friendship grew, she shared with me the pain, sorrow, and frustration that she and her family had to overcome. As I became part of the fam- ily, the happiness that had been so commonplace was harder to find... (Omidian, 1996, p. 77)

This shift from frontstage to backstage behavior was also evident in Debbie Billings' and my work with Guatemalans in Mexico. I recall asking 10-year-old Mateo, a Kanjobal Indian and the second child I interviewed in my study in the refugee camps, how he felt about returning to Guatemala in the near future. Mateo recited for me a litany of patriotic slogans about la patria (the fatherland or homeland) and cheerfully insisted that he was eager to return as soon as possible. Later that day, Mateo was taking a walk through the camp with Debbie. In the course of their conversation, the question of returning to Guatemala came up. With no tape recorder documenting his answers, and in the warmth of his informal interaction with Debbie, Mateo revealed that he actually felt scared about returning to Guatemala, and for the moment very much preferred to remain in Mexico. In the formal context of the structured, recorded research interview with me, he had offered a frontstage response, perhaps the response considered politically appropriate in the community. In the safety of his supportive, relaxed relationship with Debbie, however, he let down his mask and shared with her his "backstage" sentiments. This experience led me to pay greater attention to data gathered through informal conversations, to unobtrusively observe interactions among children and between children and the adults in their environment, and to pay closer attention to the process of developing relationships of trust with the children in each camp. ${ }^{2}$

Indigenous Guatemalans tend to be extraordinarily polite in formal social contexts in which non-Indians are present, generally reserving their critical comments for the privacy of informal social

\footnotetext{
${ }^{2}$ It is certainly possible that other factors may have influenced Mateo's decision to reveal different feelings regarding the prospect of repatriation in his earlier interaction with me and his subsequent conversation with Debbie. Gender role expectations played a powerful role in influencing the expression and perception of social behaviors in the camps, and it is possible that Mateo tailored his responses according to his perception of the kinds of feelings it would be culturally appropriate for him to share, depending on whether he was speaking with a man or a woman. In addition, values, beliefs, and feelings are not static; the very act of revealing one's values opens the door to a process of reflection on those values, and thus to the possibility that one's values will themselves change as a result of this process of revelation and reflection. It is possible, therefore, that Mateo's response to Debbie may have reflected not so much a more authentic expression of his feelings, as a more current expression of feelings that had evolved since his earlier interaction with me.
} 
interactions with trusted companions. I have participated in numerous workshops in which all or most of the participants were Indians, and the workshop leaders were either ladino (i.e., of mixed European and Indian descent) or White. In every instance, during the evaluation period the indigenous participants expressed satisfaction with the workshop and the quality of its facilitation, despite the occasionally strong feelings of dissatisfaction with some aspect of the workshop experience. This frontstage behavior can be contrasted with the backstage comments I heard in conversations with indigenous friends who had participated in several such workshops. Examples of their comments include, "That guy, he really likes to listen to the sound of his own voice," "They talk at us, but aren't really interested in a dialogue," and "He thinks he knows what the problems are in our communities, but he never asked us, so he doesn't really know." I recall being quite struck by the remarkable discrepancy between the front- and backstage behavior of Indians with regard to their experience in such mixed-ethnicity settings, and realized that an orienting marker of one's interpersonal access (i.e., as a nonIndian) to indigenous Guatemalans is the extent to which one is privy to their more critical comments not generally shared in public settings in which nonIndians are present. Consequently, Debbie and I were quite pleased one evening, several months into our stay in the larger camp, when Doña Maria (a midwife in the camp with whom we had developed a warm relationship) confided in us her frustration and indignation at the leader of a workshop which she and several other midwives in the camp had just attended on infant health. The woman leading the training, a nonindigenous Mexican nurse from a nearby hospital, refused to teach the women how to give injections, on the grounds that she was sure they would soon be inappropriately "giving injections to everyone," and adding that "Anyway, none of you can read or write" (apparently a prerequisite in her mind for being able to administer shots). Many of the women participating in the workshop, including Doña Maria, were highly skilled midwives, several of whom did in fact possess basic literacy skills. During the workshop, however, none of the women commented on the insulting and inaccurate response of the nurse to their request for instruction on giving injections. Back home, Doña Maria laughed and smiled a mischievous smile when we asked her how she felt about the workshop. In a manner suggesting that she was letting us into a private domain, she told us that she did not like the training, and felt that the nurse clearly did not know her audience very well. What's more, she added, the health promoters in the camp, all men, had been trained in giving injections, so why shouldn't the midwives also have access to this knowledge? Debbie and I agreed with her various criticisms, and reflected on the symbolic meaning of her decision to share with us her feelings of dissatisfaction. It seemed we had been invited into the backstage domain of Doña Maria's experience that evening.

There is, of course, no single moment of having "arrived" in the backstage of other people's lives. Even in the most intimate relationships there are private spaces, and an invitation into the backstage of one arena does not constitute a carte blanche invitation into the myriad other domains of an individual's personal experience. This suggests that it may be more accurate to think in terms of multiple backstages, or, alternatively, multiple private spaces, each with its own doors of admittance and exclusion. In the refugee camps, for example, we came to know a great deal about the lives of several of the participants in our research, both through formal interviews as well as informal conversations. People shared with us their experiences of loss and terror related to the violence and the exile it precipitated, their pleasure at upcoming celebrations, and their concern about the adverse impact of the summer's drought on the season's crop of corn. On the other hand, few adults spontaneously chose to talk with us about the Guatemalan guerrillas, despite the central role the guerrillas played in the evolution of the widespread violence of the early 1980s and their ongoing activity in the nearby mountains. There was virtually no mention of such social problems as spouse abuse or alcoholism, although careful observation suggested that these problems did in fact exist in the camps. In sum, we were invited to know certain domains of the refugees' lives, and not others. We became increasingly familiar and comfortable with the fluid dance between frontstage and backstage behavior, a dance which left us continually alert to the context and meaning of social interactions, and which served as an important index of interpersonal access throughout our work in the communities.

\section{The Relational Context}

Angrosino (1989), a White anthropologist, relates a fascinating story about his experience conducting a life history interview with an elderly black woman named Rebecca Levenstone from the Caribbean island of Saba. Angrosino felt the 
interview had gone well, and published his data in an anthology entitled Saba Silhouettes (Crane, 1987). A few years later, he discovered that a local black Sabian journalist had subsequently conducted another life history of Rebecca Levenstone, which was published in a local newspaper. What struck Angrosino about this second life history was the remarkable extent to which it differed from the interview that he had conducted only a few years earlier. Could it be that she had misrepresented the events of her life in one or both of narratives she provided? How could one reconcile the reality of two differing life histories from the same individual? As it turned out, however, on close examination Angrosino realized that the differences between the two life histories were not incompatible; in fact, it was evident that both histories were equally valid and complementary stories of Rebecca Levenstone's life. She had simply chosen to emphasize different aspects of her life experience in response to the unique relationship she had developed with each researcher.

The relational context of community research refers to the nature of the interpersonal relationship that develops between ourselves as researchers and those who participate in the research we conduct. There is considerable interdependence between the idea of the relational context and the previously discussed concepts of trust and interpersonal access. The development of trusting relations with community members enhances the likelihood of gaining interpersonal or "backstage" access. Consequently, a description of those relationships of trust represents a partial description of the relational context of one's research. There is more to the concept than this, however.

The idea of a relational context implies the presence of at least two important selves as they affect the research process: that of the participant, and that of the researcher. Psychologists, like other social scientists, have traditionally emphasized a detailed discussion of the former, while minimizing or omitting any discussion of the latter. We are frequently told all manner of demographic information regarding the participants in a given study, but seldom hear about the researcher's own personal characteristics, as if this information were irrelevant. We rarely read about the possible effects on the data gathering process of differences in race, ethnicity, gender, or social class between researchers and their participants. As Harding (1991, p. 58) has noted, this invisibility of the researcher reflects a deeply held belief in the capacity of the scientific method "to eliminate any social biases that might find their way from the social situation of the scientist into hypotheses, concepts, research designs, evidencegathering, or the interpretation of results."

As Scheper-Hughes (1992, p. 23) has aptly observed, this belief is convenient, in that it allow the researcher to not "examine critically the subjective bases of the questions he asked (and of those he failed to ask), the kinds of data he collected, and the theories he brought to bear on those assorted 'facts' to assemble and 'make sense' of them, to make them presentable, as it were."

More germane to the present discussion, however, is the fact that this conceptualization of the research process implies a rather odd assumption, namely, that research participants do not shape their responses to the questions we ask according to their perceptions of, and reactions to, the interpersonal (i.e., relational) context in which the research take place. This assumption implicitly characterizes participants as robotrons, responding automatically and openly, and without critical reflection on the research process itself. It reflects what Mishler (1986) has termed the "stimulus-response" model of data collection: questions are asked (the stimuli) and responses are provided by willing and cooperative subjects. This model, which arguably represents the standard approach to data collection, fundamentally ignores the interpersonal nature of the research process. Do we really believe that the use of so-called "objective" methods such as questionnaires negates the power of the relational context in the research process? Can it be that women survivors of wartime rape do not care who is asking them to complete measures that assess war-related experiences and their psychological effects? Is it plausible that male torture survivors struggling with feelings of emasculation and shame are not influenced by such factors as the gender, ethnicity, nationality, personal demeanor, and/or perceived motivation of the researchers who are asking them to rate the level of their self-esteem and the quality of their family relations?

Regardless of the methodologies we employ, whether quantitative, qualitative, or some combination of the two, I would suggest that the process of research in any community where issues of trust are particularly salient is inseparably embedded within an interpersonal context that affects both the process and outcome of the research. If we accept this premise, it becomes readily apparent that consumers of our research need to understand something of the relational context in which our data were gathered; otherwise, it is simply not possible to adequately evaluate the validity of our data and of the conclusions we reach. 
In a recent study of exile-related stressors affecting Bosnian refugees, my colleagues and I interviewed 28 adult Bosnians attending a community mental health program serving the area's Bosnian community (Miller, Worthington, Muzurovic, Tipping, \& Goldman, 2002). At the time, I was the director of the program, Greg Worthington was a practicum student, and Jasmina Muzurovic was the program's primary interpreter. The methodology involved a questionnaire assessing the salience of several exilerelated stressors, and an interview that asked participants to reflect on the experience of living in exile. Data were gathered in participants' homes, or if they preferred (which few did), in the clinic. Neither Greg nor I interviewed anyone whom we ourselves had seen in psychotherapy; however, we were both known to many of the participants because of our work in the clinic.

Having survived extraordinary levels of warrelated violence and subsequent displacement, we wondered whether clients in the program would be willing to participate in a research study with two Americans, outsiders (though not strangers) to their community. The participation of our Bosnian interpreter certainly helped facilitate a positive response to the study. It quickly became clear, however, that the participants' familiarity with me as the program's director, and with Greg as a student in the program, played a critical role in their decision to participate. For those participants' who came from rural parts of Bosnia, Greg's rural background was an important point of connection. In my own case, my family's Jewish heritage became a bridge across time and experience, as some participants linked their own experiences of genocide, flight, and survival with that of the Jews in the second World War. Among nearly all the participants, however, there was a desire to provide information that might help other Bosnians, and a belief that we were gathering data for this reason. Bosnian refugees, like other refugee groups, are generally wary of participating in research that is perceived to be purely academic. Our explicit intent to use the data from the study to inform community and clinical interventions with Bosnians was important in addressing the participants' concern that the research should be useful, that it should matter in more than some abstract, intellectual way. The authenticity of our commitment to using the data to inform psychosocial interventions with Bosnian refugees was enhanced precisely because the study's participants were acquainted with our work in the clinic.
Had we been strangers to the Bosnian community, perhaps we might still have secured the participation of community members in our study; however, that seems unlikely. We were asking people with histories of persecution and trauma to reflect aloud with us on deeply personal domains of their lives. Given this context, we came to regard both our participants' prior familiarity with us, and the interpersonal relationships that developed in the course of the interviews, not as problematic sources of bias to be controlled or eliminated, but as important aspects of the relational context that helped us gain some degree of access to the "backstage" of our participants' experiences. There is little doubt, however, that certain stories were not shared with us, that certain domains of private experience remained private during the interviews. There is also little question that some of what Greg learned in his interviews I would not have learned, and vice versa. Like Rebecca Levenstone, the participants in our research unquestionably shaped their responses according to their perception of the relational context of the research relationship; and like the anthropologist Angrosino, Greg, and I undoubtedly did the same.

\section{CONCLUSIONS}

In this paper, I have suggested that (1) gaining authentic access to refugee communities (or any community with a self-protective insularity) depends to significant extent on the development of relations of trust between researchers and community members; and (2) given the salience of issues related to access and trust in research with refugees, their neglect in the refugee mental health literature is somewhat puzzling. Two possible factors were suggested that might underlie this pattern of apparent inattention. The first factor, discussed earlier, concerns the impact on researchers of the medical/psychiatric framework that has guided much of the existing research with refugees. Within that paradigm, issues of trust and interpersonal access are generally not prioritized, because the relational context itself is viewed in fairly impersonal terms. Consequently, what I am calling a pattern of neglect would not be regarded as such; from this point of view, there is nothing neglectful about failing to discuss issues that are construed as peripheral to the research process. Throughout this paper, I have sought to illustrate the limitations of this perspective, particularly as it concerns research with refugee communities. In the absence of 
a trusting relationship, refugees may comply with requests to complete questionnaires and answer interview questions. I would suggest, however, that data gathered under such circumstances are likely to reflect "frontstage" responses that fail to accurately reflect participants' authentic life experiences.

An ecological analysis suggests a second explanatory factor. If we accept the ecological tenet that people's behavior often makes sense given the demands of their particular context, we might ask whether the lack of discussion of trust and access-related issues in the literature on refugees reflects something fundamental about the world of academic psychology in which peer-reviewed journals are published. The question is whether researchers are responding to the preferences of journal editors and reviewers, who may-at least implicitly-discourage discussion of precisely the sort of issues I have addressed in this paper. To the extent that this is so (and if it is so, it surely reflects again the power of our field's positivist roots), researchers may find themselves in the uncomfortable position of having to omit discussion of issues they know to be important.

To what extent this is an accurate depiction of our academic-scholarly environment is a matter of speculation. One clue, however, may lie in the extent to which researchers describe the process of their research differently depending on the venue for which they are writing. In contrast to scholarly journals, which represent the most stringent and most conservative scientific outlet for our research, other venues typically offer greater freedom to explore "nontraditional" ideas and issues. If there is in fact a process of self-censorship at work, in which researchers limit their discussion of certain issues based on their perceptions of particular editorial values, we should see a greater discussion of such issues in venues with greater editorial openness. Although opportunities for such comparisons are limited, there is some evidence to support this hypothesis.

The work of Punamäki $(1989,2000)$ is illustrative. In a published article examining the relationship between Palestinian children's mental health and their mothers' coping strategies with regard to violence in the West Bank and Gaza Strip, Punamäki (1989) makes no mention of how her data were actually collected, the nature of her relationship with the women and children in her study, how she convinced them to participate in her research, or what circumstances might have motivated them to provide candid responses to her research questions. Given the state of siege under which the participants in her study were living, these are not peripheral concerns. However, in a recent volume on methodological issues in research with refugees, Punamäki (2000) talks in compelling terms about the complexities of conducting research within refugee communities, and reflects on the ways in which the participants in her own research responded to and made sense of her presence and of the questions she asked. In a venue that expressly encouraged discussion of such issues, it was evident that the apparent inattention to questions of trust and access in her earlier writing were primarily a reflection of the "scholarly" values of our field and the censoring effect they exert.

Ultimately, it is a question of whether those who read our published research are to be in a position of being able to evaluate the validity of the data we present. To the extent that we accept Mishler's (1996) "stimulus-response" model of the data gathering process, discussion of issues related to trust and interpersonal access are somewhat beside the point. However, if we regard the data we collect as reflecting, at least to some extent, the unique features of the relational context in which our research is conducted, then it becomes apparent that a discussion of these issues is not merely desirable, but essential for any critical evaluation of our findings.

\section{REFERENCES}

Angrosino, M. (1989). The two lives of Rebecca Levenstone. Journal of Anthropological Research, 45, 315-326.

Billings, D. (1996). Identity, consciousness, and organizing in exile: Guatemalan refugee women in the camps of southern Mexico. Unpublished dissertation, University of Michigan, Ann Arbor.

Boothby, N. (1996). Mobilizing communities to meet the psychosocial needs of children in war and refugee crises. In R. Apfel \& B. Simon (Eds.), Minefields in their hearts: The mental health of children in war and communal violence (pp. 149-164). New Haven, CT: Yale University Press.

Crane, J. (Ed.). (1987). Saba Silhouettes. New York: Vintage.

Dawes, A., Tredoux, C., \& Feinstein, A. (1989). Political violence in South Africa: Some effects on children of the violent destruction of their community. International Journal of Psychology, $25,13-31$.

Foster-Fishman, P., Salem, D., Chibnall, S., Legler, R., \& Yapchai, C. (1998). Empirical support for the critical assumptions of empowerment theory. American Journal of Community Psychology, 26, 507-536.

Gergen, K. (1985). The social constructivist movement in social psychology. American Psychologist, 40, 266-275.

Goffman, E. (1959). The presentation of self in everyday life. New York: Doubleday.

Goodkind, J., Hang, P., \& Yang, M. (2004). Hmong refugees in the United States: A community-based advocacy and learning intervention. In K. Miller \& L. Rasco (Eds.), The mental health of refugees: Ecological approaches to healing and adaptation (pp. 295-334). Mahwah, NJ: Lawrence Erlbaum Associates, Inc. 
Guba, E., \& Lincoln, T. (1994). Competing paradigms in qualitative research. In N. Denzin \& Y. Lincoln (Eds.), Handbook of qualitative research (pp. 105-117). Thousand Oaks, CA: Sage.

Handy, J. (1984). Gift of the devil: A history of Guatemala. Boston: South End Press.

Harding, S. (1991). Whose science? Whose knowledge? Ithaca, NY: Cornell University Press.

Kelly, J. (1970). Antidotes for arrogance: Training for community psychology. American Psychologist, 25, 524-531.

Lykes, B., Maciel, R., Iborra, M., Suardi, L., \& Costa, E. (1991). Jugando a recrear nuestra historia. Talleres creativos integrales para niños. Una experiencia en Argentina y Guatemala. In E. Garcia Mendez \& M. del Carmen Bianchi (Eds.), Ser Niño en America Latina (pp. 369-374). Buenos Aires: Editorial Galerna

Manz, B. (1988). Refugees of a hidden war. Albany: State University of New York.

Mayotte, J. (1992). Disposable people: The Plight of the World's Refugees. New York: Orbis.

Miller, K. (1994). Growing up in exile: Mental health and meaningmaking among indigenous Guatemalan refugee children. Unpublished dissertation, University of Michigan, Ann Arbor.

Miller, K. (1996). The effects of state terrorism and exile on indigenous Guatemalan refugee children: A mental health assessment and an analysis of children's narratives. Child Development, 67, 89-106.

Miller, K. (1999). Rethinking a familiar model: Psychotherapy and the mental health of refugees. Journal of Contemporary Psychotherapy, 29, 283-306.

Miller, K., Worthington, G., Muzurovic, J., Tipping, S., \& Goldman, A. (2002). Bosnian refugees and the stressors of exile American Journal of Orthopsychiatry, 72, 341-354.

Miller, K., \& Billings, D. (1994). Playing to grow: A primary mental health intervention with Guatemalan refugee children. American Journal of Orthopsychiatry, 64, 346-356.
Mishler, E. (1986). Research interviewing: Context and narrative. Cambridge, UK: Harvard University Press.

Omidian, P. (1996). Aging and family in an Afghan refugee community. New York: Garland.

Oakley, A. (1981). Interviewing women: A contradiction in terms. In H. Roberts (Ed.), Doing feminist research (pp. 30-58). Boston: Routledge \& Kegan Paul.

Punamäki, R. (1989). Predictors and effectiveness of coping with political violence among Palestinian children. British Journal of Social Psychology, 29, 67-77.

Punamäki, R. (2000). Measuring suffering: Conflicts and solutions in refugee studies. In F. Ahearn (Ed.), Psychosocial wellness of refugees (pp. 105-130). New York: Berghahn Books.

Saenz, I. (1994). Un modelo para el apoyo de la salud mental de los refugiados Guatemaltecos en el sureste de México a través de la capacitacion de los promotores de la comunidad. Unpublished dissertation, Department of Psychology, National Autonomous University of Mexico.

Scheper-Hughes, N. (1992). Death without weeping: The violence of everyday life in Brazil. Berkeley: University of California Press.

Trickett, E. (1984). Toward a distinctive community psychology: An ecological metaphor for the conduct of community research and the nature of training. American Journal of Community Psychology, 12, 261-279.

Wessells, M., \& Monteiro, C. (2004). Internally displaced Angolans: A child-focused, community-based intervention. In K. Miller \& L. Rasco (Eds.), The mental health of refugees: Ecological approaches to healing and adaptation (pp. 67-94). Mahwah, NJ: Erlbaum Associates, Inc.

Zahir, G., Kakar, K., \& Miller, K. (June, 2001). Psychosocial challenges facing Afghan women refugees in the United States. Paper presented at the 8th biennial meeting of the Society for Community Research and Action, Atlanta, GA. 